\title{
Summary of Data for Quality Assessment Materials Analyzed from January 1994 through November 1998 using the NAWQA Program Bed-Sediment Analytical Protocol
}

By

\author{
Richard F. Sanzolone*
}

Open-File Report 99-588

1999

This report is preliminary and has not been reviewed for conformity with U.S. Geological Survey editorial standards and stratigraphic nomenclature. Any use of trade names is for descriptive purposes only and does not imply endorsement by the U.S. Government.

\section{U.S. DEPARTMENT OF THE INTERIOR}

U.S. GEOLOGICAL SURVEY

*U. S. Geological Survey, Box 25046, MS 973, DFC, Denver, CO 80225-0046 


\section{Table of Contents}

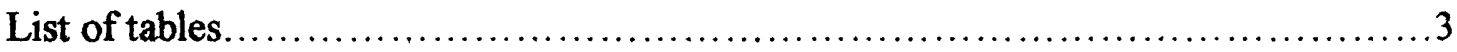

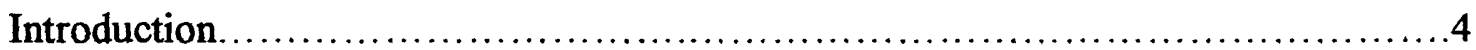

Quality Assessment Program.............................................

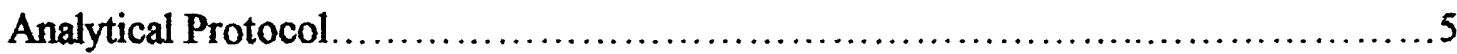

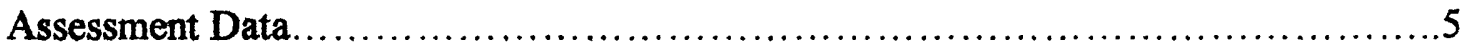

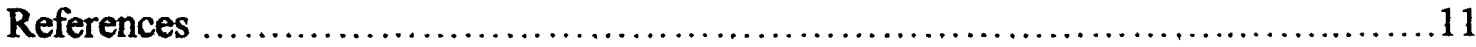




\section{List of Tables}

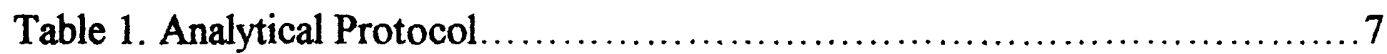

Table 2. GXR-2 values compared to literature values .........................8

Table 3. GXR-2 results compared to number of standard deviations from mean....9

Table 4. Average relative percent difference for within job analytical duplicates...10 


\section{Introduction}

This report contains a summary of the analytical data for quality assessment materials analyzed concurrently with bed-sediment samples collected by the National Water Quality Assessment (NAWQA) Program of the U.S. Geological Survey (Hirsch and others, 1988). The NAWQA bed-sediment samples were analyzed from January 1994 through November 1999 by the analytical laboratories of the Central Region Mineral Resource Surveys Team (formally the Branch of Geochemistry) of the U.S. Geological Survey. The assessment materials were analyzed to provide enhanced quality assurance for samples analyzed for the NAWQA Program.

\section{Quality Assessment Program}

Quality assurance is a critical component of a program of the scope and duration of NAWQA. The purpose of an analytical quality assurance program is to assure the reliability (precision and accuracy) of reported laboratory data, and to provide a permanent record to assure data integrity. Two concepts are involved: (1) quality control, which is the mechanism established to control errors, and (2) quality assessment, which is the mechanism to verify that the system is operating within acceptable limits (Taylor, 1981).

The approach of the quality assessment program is based on traceability, through concurrent analysis of sample duplicates and reference materials. This approach assesses both precision and accuracy but has some limitations since the ability to achieve a good result for a reference material or sample split does not guarantee a similar result for all of the natural samples analyzed. The quality assessment materials reported in this document include a geochemical reference material and sample analytical duplicates. The geochemical reference material, GXR-2, is an enriched gray-brown loam soil from a mining area (Alcott and Lakin, 1975), which was selected to provide concentrations for most constituents that are above the lower reporting limits of the analytical techniques used for determination. The sample analytical duplicates were randomly selected samples split after pulverizing to provide a duplicate sample. One reference material and one analytical sample split were inserted as double blind samples in each batch (job) of up to 38 samples submitted to the laboratory. Data from the reference material are used to assess the accuracy and long-term precision of the analysis. Data from the within batch analytical splits are used to assess the short-term precision of the analysis.

The use of assessment materials submitted along with NAWQA bed-sediment samples is in addition to the standard quality control and quality assurance practices used by the laboratory. The Laboratory QA/QC Program included the use of reference materials, duplicates, and analytical blanks. Reference materials are plotted using $\times$ (mean)-quality control charts to assess analytical bias and duplicate samples are plotted on $\mathbf{R}$ (range)quality control charts to evaluate precision. The warning and control limits are set at 2 and 3 standard deviations respectively from the mean for these charts. All data released 
for samples analyzed for the NAWQA Program meets the criteria of the Laboratory QAVQC Program. The publication "Quality assurance manual for the Branch of Geochemistry, U.S. Geological Survey" (Arbogast, 1990) describes the Laboratory QA/QC Program as well as protocols for written documentation, sample handling, sample preparation, instrumental procedures, safety protocols, and other standard procedures used by the laboratory. The laboratory also participates in various international round-robin exercises to further assess the reliability of laboratory data.

\section{Analytical Protocol}

Bed -sediment samples were wet sieved to $<63$ micron in the field according to the NAWQA protocol (Shelton and Capel, 1994). Samples were submitted to the laboratory where they are dried in a forced air oven at ambient temperature. Dried samples were processed using ceramic plate grinders and the pulverized material was put into $3 \mathrm{oz}$ cylindrical containers. The containers are then placed on mechanical rollers to homogenize the material. Table 1 shows the analytical protocol used to analyze bedsediment samples from the NAWQA Program (referred to as Schedule 2400 by Water Resources Division of the U.S. Geological Survey, National Water Quality Laboratory). This table includes the constituents determined, lower reporting limits, decomposition procedures and detection techniques used by the laboratory. A description and validation of the chemical techniques used for the NAWQA Program analytical protocol are documented in "Analytical methods manual for the Mineral Resource Surveys Program, U.S. Geological Survey" (Arbogast, 1996). The digestion procedures used are meant to be "total" for the constituents of interest. The 4-acid digestion [nitric (HNO3), hydrochloric $(\mathrm{HCl})$, perchloric ( $\mathrm{HClO} 4)$, and hydrofluoric (HF)] procedure used for the inductively coupled plasma -atomic emission spectrometric (ICP-AES) technique is considered a "total" digestion, however as with any decomposition technique dealing with natural materials there are exceptions. The digestion may not fully dissolve specific refractory, resistant, or secondary minerals. Instances of low recoveries for some elements such as $\mathrm{Ba}$ in barite, $\mathrm{Cr}$ in chromite, $\mathrm{Ti}$ in rutile, $\mathrm{Sn}$ in cassiterite, $\mathrm{Al}$ in corundum, and rare earth elements in monazite may be encountered.

\section{Assessment Data}

Table 2 shows the mean, standard deviation, percent relative standard deviation, and range of values produced by the laboratory for reference material GXR-2 along with mean consensus values from the literature and percent recovery. The data shown in table 2 addresses both accuracy and long-term precision. Percent relative standard deviation (\%RSD) ${ }^{1}$ is less than $10 \%$ for $75 \%$ of the constituents determined. Most of the

\footnotetext{
$1 \%$ RDS is calculated by dividing the mean for a particular constituent by its standard deviation and multiplying by 100 .
} 
constituents with poorer recoveries are those with concentrations near the lower reporting limit as expected. Over $85 \%$ of the constituents in GXR-2 quantified by the laboratory show a percent recovery value of $85 \%$ or greater. Notable exceptions include Al with only a 36\% recovery level. This incomplete recovery is attributed to the presence of corundum, a fact verified by independent $\mathrm{x}$-ray diffraction analysis. As stated above the multi-acid procedure used by the laboratory is not designed to completely dissolve corundum. It should also be noted that while GXR-2 is well characterized for a large number of constituents, consensus values for this material may not be "true" values. Criteria such as the number and type of determination used to produce consensus values may not meet criteria needed to qualify as a "true" or certified value.

Table 3 shows long term precision of the GXR-2 analysis. The table lists the number of times the values from the analysis of GXR-2 are within plus or minus 1,2, and 3 standard deviations of the laboratory mean. The means and standard deviations used for these tables were calculated from the laboratory data presented in table 2 . The table also lists the number of less than the lower reporting limit values (qualified values) for each constituent. Where the number of samples under the $<=3 \mathrm{~s}$ column plus the number of less than values is less than the total number of determinations (i.e. $\mathrm{Cr}$ ) the difference is the number of samples outside of 3 standard deviations from the mean. Molybdenum and Sulfur show 2 and 5 unqualified values respectively which are not tabulated because of insufficient unqualified data to determine mean and standard deviation values.

Table 4 shows within job sample duplicate data to evaluate short-term precision. The average relative percent difference (ARPD) and the average mean (mean of all duplicate means) of duplicate samples are presented. The average mean is presented to give an indication of the concentration level at which the ARPD is calculated. ARPD is a statistic often used to evaluate the precision of sample duplicates. It is calculated using the formula:

$$
\frac{\sum \frac{r}{x}}{n} \times 100
$$

Where: $r$ is the difference between the duplicate $\mathrm{x}$ is the mean of the duplicate $\mathrm{n}$ is the number of pairs of duplicates

The table also shows the number of less than values and the number of times the duplicates were both reported as less than values. In instances where duplicate analysis resulted in an unqualified and a qualified value (the number of less than values is not twice the number of less than pairs) the less than indicator was ignored for the qualified value in order to calculate the mean (x) and difference (r). The ARPD is less than $10 \%$ for $90 \%$ of the constituents and less than $5 \%$ for more than $68 \%$ of the constituents. 
Table 1.

Analytical Protocol Used for the Analysis of NAWQA Bed-Sediment Samples

\begin{tabular}{|c|c|c|c|}
\hline CONSTITUENT & DECOMPOSITION & DETECTION & LOWER REPORTING \\
\hline & TECHNIQUE & TECHNIQUE & LIMIT \\
\hline Al & (HCl $\mathrm{HNO} \mathrm{HClOA} \mathrm{HF}$ & (ICDAFSI & $0005 \%$ \\
\hline $\mathrm{Au}$ & 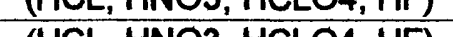 & 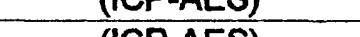 & $0.005 \%$ \\
\hline$\frac{\mathrm{Au}}{\mathrm{Bg}}$ & (HCL, HNO3, HCLO4, HF) & (ICP-AES) & 8 PPM \\
\hline $\mathbf{B a}$ & (HCL, HNO3, HCLO4, HF) & (ICP-AES) & 1 PPM \\
\hline $\mathrm{Be}$ & (HCL, HNO3, HCLO4, HF) & (ICP-AES) & 1 PPM \\
\hline $\mathrm{Bi}$ & (HCL, HNO3, HCLO4, HF) & (ICP-AES) & 10 PPM \\
\hline $\mathrm{Ca}$ & (HCL, HNO3, HCLO4, HF) & (ICP-AES) & $0.005 \%$ \\
\hline $\mathrm{Ce}$ & (HCL, HNO3, HCLO4, HF) & (ICP-AES) & 4 PPM \\
\hline $\mathrm{Co}$ & (HCL, HNO3, HCLO4, HF) & (ICP-AES) & 1PPM \\
\hline $\mathrm{Cr}$ & (HCL, HNO3, HCLO4, HF) & (ICP-AES) & 1 PPM \\
\hline $\mathrm{Cu}$ & (HCL, HNO3, HCLO4, HF) & (ICP-AES) & 1 PPM \\
\hline $\mathrm{Eu}$ & (HCL, HNO3, HCLO4, HF) & (ICP-AES) & 2PPM \\
\hline $\mathrm{Fe}$ & (HCL, HNO3, HCLO4, HF) & (ICP-AES) & $0.005 \%$ \\
\hline $\mathrm{Ga}$ & (HCL, HNO3, HCLO4, HF) & (ICP-AES) & 4PPM \\
\hline Ho & (HCL, HNO3, HCLO4, HF) & (ICP-AES) & 4 PPM \\
\hline $\mathbf{K}$ & (HCL, HNO3, HCLO4, HF) & (ICP-AES) & $0.005 \%$ \\
\hline La & (HCL, HNO3, HCLO4, HF) & (ICP-AES) & 2 PPM \\
\hline $\mathrm{Li}$ & (HCL, HNO3, HCLO4, HF) & (ICP-AES) & 2PPM \\
\hline $\mathrm{Mg}$ & (HCL, HNO3, HCLO4, HF) & (ICP-AES) & $0.005 \%$ \\
\hline $\mathrm{Mn}$ & (HCL, HNO3, HCLO4, HF) & (ICP-AES) & 4 PPM \\
\hline Mo & (HCL, HNO3, HCLO4, HF) & (ICP-AES) & 2 PPM \\
\hline $\mathrm{Na}$ & (HCL, HNO3, HCLO4, HF) & (ICP-AES) & $0.005 \%$ \\
\hline $\mathrm{Nb}$ & (HCL, HNO3, HCLO4, HF) & (ICP-AES) & 4 PPM \\
\hline $\mathrm{Nd}$ & (HCL, HNO3, HCLO4, HF) & (ICP-AES) & 4 PPM \\
\hline $\mathrm{Ni}$ & (HCL, HNO3, HCLO4, HF) & (ICP-AES) & 2PPM \\
\hline $\mathbf{P}$ & (HCL, HNO3, HCLO4, HF) & (ICP-AES) & $0.005 \%$ \\
\hline $\mathbf{P b}$ & (HCL, HNO3, HCLO4, HF) & (ICP-AES) & 4 PPM \\
\hline Sc & (HCL, HNO3, HCLO4, HF) & (ICP-AES) & 2 PPM \\
\hline Sn & (HCL, HNO3, HCLO4, HF) & (ICP-AES) & 10 PPM \\
\hline $\mathrm{Sr}$ & (HCL, HNO3, HCLO4, HF) & (ICP-AES) & 2 PPM \\
\hline $\mathrm{Ta}$ & (HCL, HNO3, HCLO4, HF) & (ICP-AES) & 40 PPM \\
\hline $\mathrm{Ti}$ & (HCL, HNO3, HCLO4, HF) & (ICP-AES) & $0.005 \%$ \\
\hline $\mathbf{V}$ & (HCL, HNO3, HCLO4, HF) & (ICP-AES) & 2PPM \\
\hline $\bar{Y}$ & (HCL, HNO3, HCLO4, HF) & (ICP-AES) & 2 PPM \\
\hline $\mathrm{Yb}$ & (HCL, HNO3, HCLO4, HF) & (ICP-AES) & 1 PPM \\
\hline $\mathrm{Zn}$ & (HCL, HNO3, HCLO4, HF) & (ICP-AES) & 4 PPM \\
\hline As & (HF, HNO3, HCLO4) & (HYDRIDE-AAS) & 0.1 PPM \\
\hline $\mathrm{Sb}$ & (HF, HNO3, HCLO4) & (HYDRIDE-AAS) & 0.1 PPM \\
\hline $\mathrm{Se}$ & $(\mathrm{HF}, \mathrm{HNO} 3, \mathrm{HClO} 4, \mathrm{H} 2 \mathrm{SO} 4)$ & (HYDRIDE-AAS) & $0.1 \mathrm{PPM}$ \\
\hline $\mathrm{Hg}$ & (HNO3, NA2CR2O7) & (COLD VAPOR-AAS) & 0.02 PPM \\
\hline $\mathrm{Ag}$ & (HF, HCL, H2O2) & (AAS) & $0.1 \mathrm{PPM}$ \\
\hline $\mathrm{Cd}$ & (HF, HCL, H2O2) & (AAS) & $0.1 \mathrm{PPM}$ \\
\hline Th & (NONE) & (DNA) & 1 PPM \\
\hline $\mathbf{U}$ & (NONE) & (DNA) & $0.1 \mathrm{PPM}$ \\
\hline Total C & (COMBUSTION) & (INFRARED) & $0.01 \%$ \\
\hline Organic C & & (BY DIFFERENCE) & $0.01 \%$ \\
\hline Carbonate C & (HCL04) & (TITRATION) & $0.01 \%$ \\
\hline $\mathrm{S}$ & (COMBUSTION) & (INFRARED) & $0.01 \%$ \\
\hline
\end{tabular}

ICP-AES = Inductively coupled plasma-atomic emission spectrometry

AAS = Atomic absorption spectrometry

DNAA = Delayed neutron activation analysis 
Table 2.

Comparison of laboratory values for reference material $G X R-2$ to literature concensus values $(n=44)$

\begin{tabular}{|c|c|c|c|c|c|c|}
\hline \multirow[b]{2}{*}{ CONSTITUENT } & \multirow[b]{2}{*}{ Mean } & \multicolumn{3}{|c|}{ LABORATORY VALUES } & \multicolumn{2}{|c|}{ CONSENSUS VALUES ${ }^{1}$} \\
\hline & & $s$ & $\%$ RSD & Range & Mean & $\%$ Recovery \\
\hline$A I^{*}$ & 6.68 & 0.42 & 6.3 & 5.8 to 7.6 & 16.46 & 40.6 \\
\hline Au & $x$ & $x$ & $x$ & $<8$ to $<8$ & 0.036 & \\
\hline $\mathrm{Ba}$ & 2181 & 91 & 4.2 & 2000 to 2400 & 2240 & 97.4 \\
\hline $\mathrm{Be}$ & 1.24 & 0.43 & 34.7 & 1 to 2 & 1.7 & 72.9 \\
\hline $\mathrm{Bi}$ & $x$ & $x$ & $x$ & $<10$ to $<10$ & 0.7 & \\
\hline $\mathrm{Ca}^{*}$ & 0.90 & 0.04 & 4.4 & 0.80 to 1.00 & 0.93 & 96.8 \\
\hline $\mathrm{Ce}$ & 51.8 & 3,3 & 6.4 & 45 to 59 & 51.4 & 100.8 \\
\hline Co & 9.2 & 0.8 & 8.7 & 8 to 11 & 8.6 & 107.0 \\
\hline $\mathrm{Cr}$ & 34.3 & 2.7 & 7.9 & 30 to 44 & 36 & 95.3 \\
\hline $\mathrm{Cu}$ & 79.8 & 3.7 & 4.6 & 71 to 91 & 76 & 105.0 \\
\hline $\mathrm{Eu}$ & $x$ & $x$ & $x$ & $<2$ to $<2$ & 0.81 & \\
\hline $\mathrm{Fe}^{*}$ & 1.92 & 0.07 & 3.6 & 1.8 to 2.1 & 1.81 & 104.3 \\
\hline $\mathrm{Ga}$ & 17.8 & 2.4 & 13.5 & 13 to 22 & 37 & 48.1 \\
\hline $\mathrm{Ho}$ & $x$ & $x$ & $x$ & $<4$ to $<4$ & no data & \\
\hline $\mathbf{K}^{*}$ & 1.30 & 0.07 & 5.4 & 1.1 to 1.5 & 1.37 & 94.9 \\
\hline La & 28.4 & 2.4 & 8.5 & 25 to 40 & 25.6 & 110.9 \\
\hline $\mathrm{Li}$ & 59.8 & 3.2 & 5.4 & 54 to 67 & 54 & 110.7 \\
\hline $\mathrm{Mg}^{*}$ & 0.845 & 0.035 & 4.1 & 0.76 to 0.96 & 0.85 & 99.4 \\
\hline $\mathrm{Mn}$ & 995 & 27 & 2.7 & 950 to 1100 & 1010 & 98.5 \\
\hline Mo & $x$ & $x$ & $x$ & $<2$ to 2 & 2.1 & \\
\hline $\mathrm{Na}^{*}$ & 0.569 & 0.032 & 5.6 & 0.52 to 0.68 & 0.556 & 102.3 \\
\hline $\mathrm{Nb}$ & 11.9 & 3.6 & 30.3 & $<4$ to 20 & 11 & 108.2 \\
\hline $\mathrm{Nd}$ & 20.9 & 1.7 & 8.1 & 18 to 25 & 19 & 110.0 \\
\hline $\mathrm{Ni}$ & 18.4 & 0.9 & 4.9 & 17 to 20 & 20 & 92.0 \\
\hline$P^{*}$ & 0.072 & 0.004 & 5.6 & 0.07 to 0.08 & 0.105 & 68.6 \\
\hline $\mathrm{Pb}$ & 681 & 46 & 6.8 & 580 to 790 & 690 & 98.7 \\
\hline Sc & 6.2 & 0.4 & 6.5 & 6 to 7 & 6.88 & 90.1 \\
\hline Sn & $x$ & $x$ & $x$ & $<5$ to $<5$ & 1.7 & \\
\hline $\mathrm{Sr}$ & 158 & 8 & 5.1 & 140 to 180 & 160 & 98.8 \\
\hline $\mathrm{Ta}$ & $x$ & $x$ & $x$ & $<40$ to $<40$ & 0.9 & \\
\hline $\mathrm{Ti}^{*}$ & 0.269 & 0.013 & 4.8 & 0.24 to 0.30 & 0.29 & 92.8 \\
\hline V & 50.9 & 2.2 & 4.3 & 47 to 58 & 52 & 97.9 \\
\hline$Y$ & 15.2 & 1.3 & 8.6 & 14 to 20 & 17 & 89.4 \\
\hline $\mathrm{Yb}$ & 1.2 & 0.4 & 33.3 & 1 to 2 & 2.04 & 58.8 \\
\hline $\mathrm{Zn}$ & 537 & 25 & 4.7 & 480 to 600 & 530 & 103.1 \\
\hline As & 23.5 & 3.1 & 13.2 & 18 to 35 & 25 & 94.0 \\
\hline Sb & 42.8 & 5.1 & 11.9 & 0.50 to 0.80 & 49 & 87.3 \\
\hline $\mathrm{Se}$ & 0.625 & 0.076 & 12.2 & 32 to 53 & 0.61 & 102.5 \\
\hline $\mathrm{Hg}$ & 3.03 & 0.25 & 8.3 & 2.1 to 3.6 & 2.9 & 104.5 \\
\hline $\mathrm{Ag}$ & 18 & 2.6 & 14.4 & 16 to 24 & 17 & 105.9 \\
\hline $\mathrm{Cd}$ & 3.95 & 0.2 & 5.1 & 3.3 to 4.1 & 4.1 & 96.3 \\
\hline Th & 8.90 & 1.24 & 13.9 & 6.35 to 11.30 & 8.8 & 101.1 \\
\hline$U$ & 3.03 & 0.15 & 4.4 & 2.51 to 3.30 & 2.9 & 104.5 \\
\hline Total C* & 2.95 & 0.056 & 1.9 & 2.77 to 3.07 & 2.5 & 118.0 \\
\hline Organic $\mathrm{C}^{*}$ & 2.94 & 0.059 & 2 & 2.76 to 3.07 & 2.59 & 113.5 \\
\hline Carbonate $\mathrm{C}^{*}$ & 0.014 & 0.009 & 64.3 & $<0.01$ to 0.05 & 0.025 & 56.0 \\
\hline $\mathrm{S}^{*}$ & $x$ & $x$ & $x$ & $<0.05$ to 0.06 & 0.0313 & \\
\hline
\end{tabular}

All values ppm except * in percent

$x=$ Insufficient unqualified data

$n=$ number of samples

$s=$ standard deviation

$\% R=$ percent recovery

\%RSD = percent relative standard deviation 
Table 3.

Fit of results of GXR-2 reference material to number of standard deviations from the laboratory means

\begin{tabular}{|c|c|c|c|c|}
\hline CONSTITUENT & No. of samples & No. of samples & No. of samples & No. of less \\
\hline & $<=1 \mathrm{~s}$ & $<=2 \mathrm{~s}$ & $<=3 s$ & than values \\
\hline & & & & \\
\hline $\mathrm{AL}$ & 34 & 41 & 44 & 0 \\
\hline $\mathrm{Au}$ & $x$ & $x$ & $x$ & 44 \\
\hline $\mathrm{Ba}$ & 36 & 43 & 44 & 0 \\
\hline $\mathrm{Be}$ & 44 & 0 & 0 & 0 \\
\hline$B i$ & $x$ & $x$ & $x$ & 44 \\
\hline $\mathrm{Ca}$ & 37 & 41 & 44 & 0 \\
\hline $\mathrm{Ce}$ & 34 & 42 & 44 & 0 \\
\hline Co & 35 & 43 & 44 & 0 \\
\hline $\mathrm{Cr}$ & 34 & 42 & 43 & 0 \\
\hline $\mathrm{Cu}$ & 30 & 42 & 43 & 0 \\
\hline Eu & $x$ & $x$ & $x$ & 44 \\
\hline $\mathrm{Fe}$ & 38 & 43 & 44 & 0 \\
\hline $\mathrm{Ga}$ & 29 & 44 & 44 & 0 \\
\hline Ho & $x$ & $x$ & $x$ & 44 \\
\hline $\mathrm{K}$ & 29 & 42 & 44 & 0 \\
\hline La & 38 & 43 & 43 & 0 \\
\hline $\mathrm{Li}$ & 37 & 43 & 44 & 0 \\
\hline $\mathrm{Mg}$ & 35 & 42 & 43 & 0 \\
\hline $\mathrm{Mn}$ & 37 & 42 & 43 & 0 \\
\hline Mo & $x$ & $\bar{x}$ & $x$ & 42 \\
\hline $\mathrm{Na}$ & 36 & 42 & 43 & 0 \\
\hline $\mathrm{Nb}$ & 31 & 42 & 43 & 1 \\
\hline Nd & 29 & 43 & 44 & 0 \\
\hline $\mathrm{Ni}$ & 35 & 44 & 44 & 0 \\
\hline $\mathrm{P}$ & 35 & 44 & 44 & 0 \\
\hline $\mathrm{Pb}$ & 31 & 42 & 44 & 0 \\
\hline Sc & 34 & 44 & 44 & 0 \\
\hline Sn & $\mathbf{x}$ & $x$ & $x$ & 44 \\
\hline$S r$ & 36 & 41 & 44 & 0 \\
\hline Ta & $x$ & $x$ & $x$ & 44 \\
\hline $\mathrm{Ti}$ & 34 & 42 & 44 & 0 \\
\hline V & 35 & 42 & 43 & 0 \\
\hline$Y$ & 36 & 42 & 43 & 0 \\
\hline$Y b$ & 36 & 44 & 44 & 0 \\
\hline $\mathrm{Zn}$ & 32 & 41 & 44 & 0 \\
\hline As & 33 & 42 & 43 & 0 \\
\hline$S b$ & 35 & 41 & 44 & 0 \\
\hline $\mathrm{Se}$ & 30 & 43 & 44 & 0 \\
\hline $\mathrm{Hg}$ & 36 & 42 & 43 & 0 \\
\hline $\mathrm{Ag}$ & 37 & 39 & 44 & 0 \\
\hline$\overline{C d}$ & 35 & 39 & 43 & 0 \\
\hline Th & 28 & 43 & 44 & 0 \\
\hline U & 29 & 39 & 43 & 0 \\
\hline Total C & 36 & 41 & 43 & 0 \\
\hline Organic C & 35 & 42 & 44 & 0 \\
\hline Carbonate C & 27 & 27 & 27 & 16 \\
\hline s & $x$ & $x$ & $x$ & 39 \\
\hline
\end{tabular}


Table 4.

Average relative percent difference and average mean for within job sample duplicates ( $n=44$ pair)

\begin{tabular}{|c|c|c|c|c|}
\hline CONSTITUENT & Average Relative & Average Mean & No. Less Than Values & No. Less Than Pairs \\
\hline & Percent Difference & & & \\
\hline & & & & \\
\hline $\mathrm{AL}$ & 2.3 & $6.6^{\star}$ & 0 & 0 \\
\hline $\mathrm{Au}$ & $\mathbf{x}$ & $<8$ & 88 & 44 \\
\hline $\mathrm{Ba}$ & 2.0 & 526 & 0 & 0 \\
\hline $\mathrm{Be}$ & 4.2 & 2 & 8 & 4 \\
\hline $\mathrm{Bi}$ & $x$ & $<10$ & 88 & 44 \\
\hline $\mathrm{Ca}$ & 3.0 & $4.3^{*}$ & 0 & 0 \\
\hline $\mathrm{Ce}$ & 3.7 & 73 & 0 & 0 \\
\hline Co & 3.7 & 16 & 0 & 0 \\
\hline $\mathrm{Cr}$ & 2.7 & 68 & 0 & 0 \\
\hline $\mathrm{Cu}$ & 5.1 & 29 & 0 & 0 \\
\hline $\mathrm{Eu}$ & $x$ & $<2$ & 85 & 42 \\
\hline $\mathrm{Fe}$ & 1.3 & $3.5^{*}$ & 0 & 0 \\
\hline $\mathrm{Ga}$ & 5.9 & 16 & 2 & 1 \\
\hline $\mathrm{Ho}$ & $x$ & $<4$ & 88 & 44 \\
\hline $\mathrm{K}$ & 3.1 & $1.5^{*}$ & 0 & 0 \\
\hline La & 4.4 & 39 & 0 & 0 \\
\hline Li & 2.9 & 36 & 0 & 0 \\
\hline $\mathrm{Mg}$ & 1.2 & $1.08^{*}$ & 0 & 0 \\
\hline $\mathrm{Mn}$ & 1.6 & 1112 & 0 & 0 \\
\hline Mo & $x$ & $<2$ & 86 & 43 \\
\hline $\mathrm{Na}$ & 2.7 & $0.8^{*}$ & 0 & 0 \\
\hline $\mathrm{Nb}$ & 8.5 & 14 & 4 & 2 \\
\hline Nd & 5.8 & 36 & 4 & 2 \\
\hline $\mathrm{Ni}$ & 3.1 & 32 & 0 & 0 \\
\hline$P$ & 4.6 & $0.09^{\star}$ & 0 & 0 \\
\hline $\mathrm{Pb}$ & 11.4 & 28 & 1 & 0 \\
\hline Sc & 1.2 & 12 & 2 & 1 \\
\hline Sn & $x$ & $<5$ & 88 & 44 \\
\hline $\mathrm{Sr}$ & 1.5 & 285 & 0 & 0 \\
\hline $\mathrm{Ta}$ & $x$ & $<40$ & 88 & 44 \\
\hline $\mathrm{Ti}$ & 3.8 & $0.42^{*}$ & 0 & 0 \\
\hline V & 2.5 & 99 & 0 & 0 \\
\hline $\bar{Y}$ & 3.0 & 23 & 0 & 0 \\
\hline $\mathrm{Yb}$ & 8.6 & 2 & 4 & 1 \\
\hline $\mathrm{Zn}$ & 2.8 & 114 & 2 & 1 \\
\hline As & 6.3 & 8.7 & 0 & 0 \\
\hline $\mathrm{Sb}$ & 22.4 & 0.90 & 4 & 1 \\
\hline $\mathrm{Se}$ & 7.2 & 0.72 & 4 & 2 \\
\hline $\mathrm{Hg}$ & 17.7 & 0.090 & 13 & 5 \\
\hline $\mathrm{Ag}$ & 3.6 & 0.32 & 11 & 4 \\
\hline Cd & 8.5 & 0.400 & 3 & 1 \\
\hline Th & 14.2 & 10.8 & 4 & 2 \\
\hline $\mathrm{U}$ & 7.6 & 3.95 & 0 & 0 \\
\hline Total C & 0.7 & $3.11^{*}$ & 0 & 0 \\
\hline Organic C & 2.7 & $1.86^{*}$ & 0 & 0 \\
\hline Carbonate C & 4.2 & $1.44^{*}$ & 12 & 5 \\
\hline$s$ & 3.4 & $0.13^{*}$ & 25 & 12 \\
\hline
\end{tabular}




\section{References}

Alcott, G. H., and Lakin, H. W., 1975, Geochemical exploration 1974: in Elliott, I. L., and Fletcher, W. D., Editors, Elseveir, Amsterdam, 659 p.

Arbogast, B. F., 1990, Quality assurance manual for the Branch of Geochemistry, U. S. Geological Survey: U.S. Geological Survey Open-File Report 90-668, 184 p.

Arbogst, B. F., 1996, Analytical methods manual for the Mineral Resource Surveys Program, U.S. Geological Survey: U.S. Geological Survey Open-File Report 96$525,248 \mathrm{p}$.

Gladney, E. S., and Roelandts, I., 1990, 1988 compilation of elemental concentration data for USGS geochemical reference materials GXR-1 to GXR-6: Geostandards Newsletter, 14, p. $21-118$.

Hirsh, R. M., Alley, W. M., and Wilber, W. G., 1988, Conceptual design of a National Water Quality Assessment Program: U.S. Geological Survey Circular 1021, 42p.

Shelton, L. R, and Capel, P. D., 1994, Guideline for collecting and processing samples of stream-bed sediment for analysis of trace elements and organic contaminants for the National Water Quality Assessment Program: U.S. Geological Survey OpenFile Report 94-458, 20p.

Taylor, J. K., 1981, Quality assurance of chemical measurements: Analytical Chemistry, v. 53 , no. 14, p. $1588-1596$. 